\title{
VII. Report presented to the class of the exact Sciences of the Academy of Turin, 15th August 1802 , in regard to the Galvanic experiments made by C. Vassali-Eandi, Giulio, and Rossi, on the 10 th and 14th of the same month, on the head and trunk of three men a short time after their decapitation
}

\section{Giulio}

To cite this article: C. Giulio (1803) VII. Report presented to the class of the exact Sciences of the Academy of Turin, 15th August 1802, in regard to the Galvanic experiments made by C. Vassali-Eandi, Giulio, and Rossi, on the 10th and 14th of the same month, on the head and trunk of three men a short time after their decapitation, Philosophical Magazine Series 1, 15:57, 38-45, DOI: $10.1080 / 14786440308676227$

To link to this article: http://dx.doi.org/10.1080/14786440308676227

Published online: 18 May 2009.

\section{Submit your article to this journal $\square$}

Џلl Article views: 2 
India. In cafe of any diftant expeditions, they would be found fuperior, being entirely free from all religious prejudices, and having no objection to the fea.

While Cochin China remains in its prefent diftracted ftate, a favourable opening is prefented to the firft European nation that may attempt to obtain a footing in the country. Should the company, therefore, entertain a defign of forming: an eftablifhment in Cochin China, no time fhould be loft in carrying it into execution.

VII. Report prefented to the Clafs of the Exact Sciences of the Academy of Turin, ${ }^{5}{ }^{t h}$ Augufl $\mathrm{I} 802$, in regard to tbe Gulvanic Experiments made by C. VASSA LI-EANDI, Givlro, and Rossi, on the Ioth and 14 th of the fame Montb, on the Head and Trunk of three Men a Jbort Time after their Decapitation. By C. Giulio.

\section{$\mathrm{T}$}

HE Firft Conful, in a letter to Chaptal, in which he announced to that minifter the two prizes he had founded to encourage philofophers to make new refearches in regard to Galvanilm, fays, "Galvanifm, in my opinion, will lead to great difcoveries." This obfervation was juft and profound: great difcoveries have already been made; Galvani and Volta have immortalized their names, and feveral celebrated philofophers and phyfiologifts have rendered themfelves illuftrious in this branch of feience, to abundant in aftonifhing phænomena : yet it is only in its infancy, and there can be no doubt that many important difcoveries ftill remain to be made.

Vaffali, Roffi, and myfelf, have for feveral years been employed in refearches on this fubject. While the firit examined the Galvanic fluid in every point of view, for the purpofe of illuftrating its nature by means of a great number of ingenious experiments, performed with that care and exactnefs which are peculiar to him, Roffi and myfelf attempted to explain the action of the Galvanic fluid on the different organs of the animal economy.

Sonjetimes I was obliged to interrupt my refearches by unfortunate circumftances, and at others by my adminiftrative functions : but I have now refumed them; and though fuccefs has not yet crowned my efforts by any brilliant difcovery, we truft, and with confidence, that we thall be able to add fome valuable facts to the hiftory of the animal economy; to rectify errors; to confirm facts already received; and 
to extend the domain of an inexhauftible agent fertile in wonders.

Volta had announced that the involuntary organs, fuch as the heart, the ftomach, the inteftines, the bladder and veffels, are infenfible to the Galvanic action *: but we have fully refuted this great phyfiological error. Unfortunately, however, the Latin memoir containing the decifive experiments which we made on cold-blooded and warm-blooded animals in 1792, prefented to the Academy foon after, and which, according to Sue, in his Hiftory of Galvanifm t, "are curious, and contain very interefting obfervations," did not appear till 180r, when it was printed in the laf volume of the Tranfactions of the Academy.

In that interval Grapengieffer found, as we had done, that Galvanifin, by means of zinc and filver $\ddagger$, has an influence on the periftaltic motion. Humboldt afcertained the Galvanic action on the hearts of frogs, lizards, toads, and fifhes. Smuch obferved the excitability of the heart by the Galvanic fluid; and Fowler changed the pulfations of the heart without the immediate application to it of armatures, and only by adapting them in warm-blooded animals to the recurrent nerve by means of the fympathetic $\S$.

It is chiefly in regard to the experiments of thefe learned Germans that the hiftorian of Galvanifm ftates \|, that the involuntary vermicular motion of the inteftines, according to the acknowledgment of all phyfiologilts, obeys metallic irritation; whence it follows, fays he, that the Italian philofophers have advanced an error when they faid that Galvanifm exercifes no action but on the mufcles, which depend on the will. As an accurate and impartial biftorian, how can Sue accufe the Italian philofophers indifcriminately of fuch an error, fince he had our memoir before him when employed on the fecond volume of his Hiftory of Galvanifm, and fince he gave a fhort account of my experiments in his firft volume? Nay, I gave an account of my experiments in a fmal! work publithed in Italian in $\mathbf{1 7 9 2 . ~ B u t ~ a s ~ I t a l i a n ~ w o r k s ~ a r e ~}$ not much read in France, and were lefs fo at that period, I thould not have reproached C. Sue with this act of injuftice,

* Mezzini, Volta, Valli, Klein, Pfaff, Berhends, hars denied that the heart conld be moved by the Galvanic fluid. Hifl. du Gulvanijme, part i. p. 145. B1chat could obtain no contractions etther in the heart of man or that of the dog. See Récherches Pbyfiologiques fur la Vie et la Mort.

+ Towards the end of the firt part.

+ See Hiflaire du Gidvanifme, vol ii. p. $8 \mathrm{I}$.

Ilbid. vol. ii. p. 84 . || Vol. ii. p. 83 . 
and his incorrectnefs in regard to the Italian philofophers, had not my Latin memoir been known to him, as it had appeared in the Tranfactions of the Academy.

Though we made a great many experiments before we attempted to combat a philofopher fo juftly celebrated as Volta, and to eftablith the influence of Galvanifin on the involuntary organs; and though Grapengieffer, Humboldt, Smuch, Fowler, \&c. afcertained this influence in certain cold-blooded and even warm-blooded animals; an object of fo much importance to phyfiology required to be extended and confirmed, efpecially in man, by new experiments. We have been the more fenfible of the neceffity of eftablifhing this fact in an inconteftable manner, either in regard to the involuntary organs in general, or more particularly the heart, as the celebrated Aldini, profeftor of Bologna, in an Italian work replete with new facts and valuable experiments made on the bodies of decapitated criminals, has been obliged to acknowledge that he was not able to obtain any contraction in that organ' by means of the electro-motor of Volta, which is fo powerful.

We thall give an account, in particular memoirs, of the experiments we have alrcady made, and of thofe which we propofe to execute. In regard to the ftomach, the large and the fmall inteftines, and the bladder, we thall fay only, in a general manner, that by armature of the different nervous branches we obtained contractions analogous to thofe defcribed in regard to animals. The Galvanic action on the heart and arteries is the object of the prefent paper, as it is of the utmoft importance to phyfiology, and deferves, under every point of view, to excite our attention and occupy our reflections.

Our experiments on the different parts of the head and trunk of the decapitated criminals were begun, on the roth of Auguft, in a hall of the large hofpital of St. John, and refumed and continued yefterday in the anatomical theatre of the univerity, - before a great number of fpectators.

We tried the influence of Galvanifm on the heart in three different ways :

Ift, In arming the fpinal marrow by means of a cylinder of lead introduced into the canal of the cervical vertebra, and then conveying one extremity of a filver arc over the furface of the heart, and the other to the arming of the fpinal marrow. The beart of the firft individual fubjected to our experi.nents immediately exhibited very vifible and very ftrong contractions. Thefe experiments, as feen, were made with- 
out any intervention of the pile, and without any armature applied to the beart. It is very remarkable, that when the former is touched firft, and then the arming and fpinal marrow, the contractions of the heart which follow are more inftantaneous, and ftronger, than when the arming of the fpinal marrow is firtt touched, and then the heart. In a memoir on Galvanifm, read in the laft public fitting of the academy, I gave an account of a great number of experiments, made efpecially on frogs, which exhibited a fimilar phænomenon. In thefe animals I obferved, a great number of times, that when the arming of the crural nerves was touched firft, and then the mufcles of the thigh, there were no contractions, or the contractions were exceedingly weak; and, on the other hand, that when the mufcles of the thighs were firft touched, and then the arming of the crural nerves, as long as the leaft vitality remained in the organs the contractions of the mufcles were conftant and violent. In the memoir already mentioned I have endeavoured to account for this phænomenon, to which I fhall recur when, by a great number of trials, we thall have afcertained that it is as general in men as $I$ found it in frogs and other cold-blooded animals.

The fecond manner in which we tried the influence of Galvanifm on the heart was by arming the nervi vagi and the large fympathetic. The object of thefe experiments will be readily comprehended by anatomifts acquainted with the details of neurology. In thefe, as well as in the firt and other experiments where we armed the cardiac nerves themfelves, we obtained contractions in the heart. In this, as in the former cafe, the contractions obtained when the heart was firft touched, and then the arming of the nerves, were much ftronger than when the arming of the nerves was touched firt, and then the heart. In this method we even obferved that the Galvanic experiments fometimes failed.

The third kind of experiments on the heart were performed by means of the pile. The pile we employed on the roth of Auguft, for the experiments on the firft decapitated criminal, was compofed of fifty plates of filver and as many of zinc, with pafteboard moiftened with a ftrong folution of muriate of foda. The filver was mixed with a tenth part of copper. This is the proportion which we found moft favourable to the intenfity of the figns of Galvanifm:

The diameter of the filver plates was - Metre.

Their thicknefs - - - 0.0015

The dimentions of the pieces of palteboard were the fame. 
$\begin{array}{lll}\text { The diameter of the zinc plates was } & - & \text { Metre. } \\ 0.042 \\ \text { Their thicknefs }\end{array}$

The pile employed for the experiments on the $15^{\text {th }}$ of Augual was compofed of fifty plates of pure filver, and twice that number of plates of zinc and pieces of pafteboard; the latter moiftened in a folution of muriate of foda.

The diameter of the filver plates was $-\quad \begin{aligned} & \text { Metre. } \\ & 0.038\end{aligned}$

Their thicknefs - - - $0.00 \mathrm{r}$

The dimenfions of the pieces of pafteboard were the fame.

The diameter of the zinc plates was $\quad-\quad 0.04$

Their thicknefs - $\quad$ - $\quad$ - 0.001

By making the negative extremity of the pile to communicate, by means of refpective conductors, with the fpinal marrow, or merely with the mufcles of the back or brealt, laid bare, and the pofitive extremity immediately with the heart, inftantaneous and violent contractions were obtained; and the contractions were produced alfo when the heart was made to communicate with the negative extremity of the pile, and the fpinal marrow with the pofitive extremity.

We thall obferve, in regard to contractions of the heart, that of all its parts the apex is the moft fufceptible of motion, and the moft fenfible to the Galvanic influence: we muft obferve alfo, that the contractions produced by communication with the pile were not only ftrong, but that they continued a long time even after all the communication was removed.

A very remarkable circumftance is, that the heart, which of all the mufcles retains longeft, in general, its contractility in regard to mechanical ftimulants, is the firft to become infenfible to the Galvanic influence. The mufcles of the arms, and thofe of the back and breaft, continue to be excitable by Galvanifm for whole hours; and the heart had loft its excitability about forty minutes after death.

The experiments made yefterday in the anatomical theatre exhibited nearly the fame refults in regard to the heart as thofe already mentioned. The great arteries, fuch as the aorta and fome of its branches, being injected with water raifed nearly to the fame temperament as that of the blood in the living individual, when fubjected to the Galvanic action exhibited contractions. But it is probable that they will appear ftronger when trials of this kind thall be made on bodies endowed with a higher degree of vitality than thofe of yefterday, and when the interval between the period of decapitation 
decapitation and that of the experiments thall be lefs. With this view, indeed, we have provided a hall much nearer to the place of execution; for the refults which we obtained in the man decapitated on the roth of Auguft, in which cafe the experiments were begun five minutes after the decapitation, were all comparatively more ftriking, and ftronger, than thofe obtained in the experiments of yefterday, which were begun more than twenty minutes after decapitation, and which were performed, as appears, on bodies endowed with a much weaker degree of vitality.

In the experiments made on the arteries, we armed the nervous plexus, which envelop the trunks of the coeliac and mefenteric arteries, feveral branches of which are even interwoven around the aorta: a communication was eftablithed between the pofitive or negative extremity of the pile and the aortic artery itfelf. It was by thefe means that we obtained rifible contractions.

If the effects of Galvanifm on arterial contractions are conftant, as I prefume, all thofe difcuffions which have been agitated fo long, and with fo much violence, in regard to the irritability of the arteries, which does not manifeft itfelf by the action of different mechanical and chemical ftimulants, will at length be terminated in a pofitive and irrefragable manner; all doubts will at length be removed; and we thall be indebted to the Galvanic fluid, which is the moft energetic of all agents applied to the animal fibre, for having fixed the opinions of phyfiologifts on a point of fo much importance to the animal economy.

Whence comes it that Aldini, even with the help of the moit powerful electro-motors, was not able to obtain contractions in the heart of man, which we fo evidently obtained by the fame means which always withftood his efforts? How happens it that we obtained contractions by means much weaker?

The firft experiments of Aldini on the human heart were begun an hour and a half after death *. The trunk had been expofed a long time to the open air, the temperature of which was no more than +2 . It is probable that the cold, and the long interval between the period of death and that of the experiment, had already annihilated the irritability of the heart $t_{0}$ In the fifty-third experiment, the heart of another executed

* Saggio di Sperienze ful Galvanifmo di Gioani Aldini; Bolonia x 802, p. 14, elip. 28 ,

$\uparrow$ If the celebrated Bichat failed in his experiments on the human heart, as well as Aldini, it was, perhaps, owing to the fame caufes. The tem- 


\section{Vaffali-Eandi, Giulio, and Rofi's Galvanic Experiments}

executed criminal conftantly remained motionlefs and infenfible to the Galvanic current. But in this experiment, before trying the heart, a conffderable time was employed in making trials on the voluntary organs, the fenfibility of which to Galvanifm had already been acknowledged. But the very reverfe of this method ought to be followed; for I will here repeat, that excitability, by means of the Galvanic fluid, is extinguifhed in the heart a long time before it becomes extinct in the voluntary mufcles. This is fo certain, that while no part of the heart, tried externally and internally, prefented any frgn of contractions, the diaphragm, and the mufcles of the upper and lower extremities, gave very ftrong ones.

In our experiments which were begun five minutes after death, the heart ceafed to be fenfible to the Galvanic agent about the fortieth minute; and this was the cafe in the temperature of +25 ; while the voluntary mufcles retained their Galvanic excitability for whole hours. In other experiments made by Aldini, the contractility of the voluntary mufcles exifted three hours, and even five hours, after death.

In the oxen fubjected to Galvanic experiments by Aldini, the excitability of the heart muft have been extinguifhed fooner, fince the action of the Galvanic fluid of the pile produced no contractions, though applied immediately after death.

If contractions were obferved in the voluntary mufcles under the fame circumftances, it was becaufe thefe mufcles, which lofe much fooner than the heart their excitability in regard to mechanical ftimulants, retain it much longer than that organ in regard to the Galvanic agent. What then is the caufe of this diverfity, which feems contrary to every analogy, and which, however, is proved by facts? It is fill involved in much obfcurity: but it is not yet time to tear the dark veil which conceals it; we are not yet enlightened by a fufficient number of facts; and the few fcattered data which we have been able to collect, cannot yet be connected in a manner capable of encouraging us to attempt to rend the veil at prefent.

We thall not here fpeak of the aftonifhment with which the fpectators were ftruck when they faw the contractions of

perature was cold, and the interval between the time of execution and that of the experiment too long. "I was authorized," fays Bichat, " in tire winter of the year 7 , to make various trials on the bodies of unfortun te perfons who had been guillotined. I had them at my difpofal from thrty to forty minutes after execution. It was always impoffible for me to produce the leaft notion by arming either the fpinal marrow and the heart, or the latter organ and the nerves which it receives from the ganglion by the fympathetic, or from the brain by the par vagum. 
the frontal mufcles, thofe of the eye-lids, the face, the lower jaw, and the tongue; when they beheld the convulfions of the mufcles of the arms, the breaft, and of the back, which raifed the trunk fome inches from the table; the contractions of the pectoral mufcles, and the exterior and interior intercoftal mufcles, which diminifhed the intervals between all the ribs, and made them approach each other with violence, raifing the inferior ones towards the fuperior, and the latter towards the firft rib and the clavicle; the contractions of the arms, which, when the uncovered biceps mufcle was touched, as well as its tendon, were fo fpeedy and violent, that complete flexion of the fore-arm on the arm took place, and that the hand raifed weights of fome pounds fifty minutes after decapitation. Similar experiments may be feen in the work of Aldini : our object in this report was merely to fpeak of the Galvanic influence on the heart and arteries of man, which bad not yet been obferved.

Thefe new and important refults, which we obtained in regard to the heart and arteries of man, will be confirmed by other trials. We hall repeat our experiments as foon as an opportunity occurs, and we thall take care to give you an early account of the moft remarkable obfervations we thall make.

VIII. A Review of fome Experiments wbicb bave been fuppofed to difprove the Materiality of Heat. By WILLIAax HEN R * *

T HE following remarks on the fubject of heat were written foon after the publication of Count Rumford's Inquiry concerning the Source of the Heat evolved by Friction; and of the interefting Effays of $\mathrm{Mr}$. Davy, which appeared in Dr. Beddoes's Weft Country Contributions. They were tranfmitted to Dr. Beddoes, for publication, about the clofe of the year 1799; but circumftances, with which I am unacquainted, have, I believe, induced the doctor to decline the continuation of his periodical work. Thefe circumftances I deem it neceffary to ftate; becaufe, had the effay been written nearer the period of its publication, it would probably have affumed a very different form. At prefent, I have not leifure to review the fubject, or to attempt any material alteration; and fill lefs to examine whether I have been anticipated by any of the authors whole effays have been publithed during the two laft years.

* From the Mancbefler Society's Tranfactions, vol, v, part 2. 